\title{
O "olhar preconceituoso": Representações sociais sobre fotografias nas redes sociais
}

\section{The "look prejudiced": Social representations of photographs on social networks}

\section{Representaciones sociales de fotografías en las redes sociales: la "mirada prejuiciosa"}

\author{
Larissa Papaleo Koelzer* \\ Universidade Federal de Santa Catarina - UFSC, Florianópolis, Santa Catarina, \\ Brasil
}

\author{
Amanda Castro** \\ Universidade Federal de Santa Catarina - UFSC, Florianópolis, Santa Catarina, \\ Brasil
}

\section{Andréa Barbará S. Bousfield***}

Universidade Federal de Santa Catarina - UFSC, Florianópolis, Santa Catarina, Brasil

\section{Brigido Vizeu Camargo****}

Universidade Federal de Santa Catarina - UFSC, Florianópolis, Santa Catarina, Brasil

\begin{abstract}
RESUMO
O objetivo deste estudo foi analisar comentários na internet oriundos de uma reportagem online envolvendo fotografias. As fotos apresentam uma mulher obesa, loira e branca, realizando diversas atividades em lugares públicos. As fotos destacam o olhar das pessoas que observam as ações desta mulher, sendo que nessa reportagem online tais olhares são associados à expressão de preconceito. Foram analisados 172 comentários online, dentre os quais $50 \%$ pertenciam a pessoas do sexo masculino. Cada comentário poderia ser classificado por outros internautas como positivo e $78 \%$ dos comentários postados foram positivados pelos participantes. Para a análise dos dados foi utilizada a técnica de análise lexical de conjuntos de segmentos de texto, na qual os comentários foram submetidos a uma Classificação Hierárquica Descendente (CHD) realizada pelo programa informático Iramuteq. As classes geradas após a análise apresentam elementos que indicam a atuação das normas sociais, por meio da atribuição de uma representação a outro, o que caracteriza a zona muda, por adequação à norma antidiscriminatória ou atribuição do preconceito justificado na ação do indivíduo alvo de discriminação. Desse modo, os resultados evidenciados pela CHD denotam que a obesidade parece ocupar espaço na zona muda nas representações sobre o "olhar preconceituoso".
\end{abstract}


Palavras-chaves: preconceito, obesidade, fotografia, representações sociais.

\begin{abstract}
The aim of this study has been to analyze commentaries on the Internet related to an online article involving photographs. The photos show an obese, blonde and white woman, performing several activities on public sites. The photos highlight on the glance of the people that observe these woman's actions, as the online article associates these glances with expressions of prejudice. 172 online commentaries were analyzed, 50\% of them coming form male subjects. Each commentary can be tagged as positive by other Internet users, and $78 \%$ of the online commentaries were tagged as positive by participants. To analyze the data, the study used a technique of lexical analysis of groups of text segments, which submitted the commentaries to a Descendent Hierarchical Classification (DHC), executed by the Iramuteq software. The classes generated after analysis show elements that indicate the performance of social rules, through the attribution of a representation of the other, which characterizes a mute zone, due to the adaptation to the anti-discriminatory rule or to the attribution of a justified prejudice due to the action of the individual being discriminated. Thus, the results offered by the DHC evidence that obesity seems to occupy a space on the mute zone of the representations related to a "prejudicious glance".
\end{abstract}

Keywords: prejudice, obesity, photography, social representations.

\title{
RESUMEN
}

El objetivo de este estudio ha sido el de analizar comentarios en Internet en torno a un reportaje online que incluye fotografías. Las fotos muestran una mujer obesa, rubia y blanca, realizando diversas actividades en espacios públicos. Las fotos resaltan la mirada de las personas que observan las acciones de esta mujer, ya que en este reportaje online se asocian estas miradas a una expresión de prejuicio. Fueron analizados 172 comentarios online, de los cuales $50 \%$ pertenecen a personas del sexo masculino. Cada comentario podría ser clasificado por otros internautas como positivo y el $78 \%$ de los comentarios publicados fueron clasificados como positivos por los participantes. Para el análisis de los datos se utilizó la técnica de análisis lexical de conjuntos de segmentos del texto, con la cual los comentarios fueron sometidos a una Clasificación Jerárquica Descendente (CJD) realizada por el programa informático Iramuteq. Las clases generadas después del análisis presentan elementos que señalan la actuación de las normas sociales, por medio de la atribución de una representación a otro, lo que caracteriza la zona muda, por adecuación a la norma antidiscriminatoria o por atribución de un prejuicio justificado por la forma de actuar del individuo sujeto de discriminación. De este modo, los resultados evidenciados por la CJ $D$ evidencian que la obesidad parece ocupar un espacio en la zona muda de las representaciones sobre la "mirada prejuiciosa".

Palabras claves: prejuicio, obesidad, fotografía, representaciones sociales.

\section{Introdução}

Com grande frequência a mulher é percebida e valorizada de acordo com sua aparência física e a literatura corrobora isso (Camargo, 
Goetz, Bousfield, \& Justo, 2011; Goetz, 2013; Tolman, \& Debold, 1994; Wolf, 1992). No contexto social, o corpo magro adquiriu sentido de corpo ideal, estando em evidência nu ou vestido, exposto em diversas revistas femininas e masculinas, associado à moda e se transformando no sonho de consumo de milhares de pessoas (Vasconcelos, Sudo, \& Sudo, 2004). Essa valorização do corpo magro tem por consequência o movimento de rejeição da sociedade em relação à figura do gordo e do obeso (Fischler, 1995; Stearns, 1997). Desse modo, Dantas (1994) sugere que essa exaltação ao corpo não passa de uma forma mascarada de menosprezá-lo.

A beleza está associada ao corpo magro. Nesse contexto, a feiura tornou-se sinônimo de um corpo fora dos padrões de beleza socialmente estabelecidos, sendo esta uma das formas mais frequentes de exclusão social feminina na atualidade. A imagem da mulher e do feminino aparece associada à beleza e cada vez menos são tolerados os desvios nos padrões estéticos socialmente estabelecidos (Novaes \& Vilhena, 2003).

O corpo não só é o representante da individualidade, mas também é um meio de interação social, inserido num contexto, por isso trata-se de um objeto relevante a ser estudado no domínio da Psicologia Social. A Psicologia Social ocupa-se de estudar o homem na sociedade, suas relações e as interações estabelecidas no contexto social em que se insere. Nesse sentido, ela pode ser considerada uma ciência social que tem como objeto de estudo as relações cotidianas produzidas na realidade social, os fenômenos relacionados à comunicação e a ideologia, ou seja, o conhecimento e as representações sociais (Palmonari \& Cerrato, 2011).

As representações sociais, de acordo com Moscovici (2000), são um conjunto de conceitos, afirmações e explicações originadas no dia a dia, durante a comunicação e cooperação entre os indivíduos e grupos. Estas não são mero reflexo da realidade introduzida passivamente no sujeito, mas uma significativa reorganização na qual estão estruturados o pensar e o agir (Jodelet, 1989a; Moscovici, 1978).

O contexto social e ideológico, o lugar ocupado pelo indivíduo no grupo, sua história, os determinantes sociais, sistemas e valores influenciam essa organização significante chamada representação social. Por sua importância na vida social as representações sociais são tidas como objeto de estudo tão legítimo quanto o científico (Jodelet, 2001). Moscovici (1981) esclarece sobre a legitimidade desse conhecimento ao diferenciar os universos consensuais e universos reificados (J odelet, 2001; Moscovici, 1981).

Nos universos consensuais a sociedade se percebe como um grupo constituído por indivíduos de igual valor, sendo cada indivíduo livre para se comportar como um "amador" e "observador curioso". Tais universos desenvolvem formas costumeiras de realizar determinadas 
práticas e uma série de significados entre aqueles que participam dele, a fim de que o indivíduo esteja protegido das áreas de discordância e de incompatibilidade.

Já nos universos reificados a sociedade é vista como um sistema composto por diferentes papéis e categorias, cujos ocupantes estão em grupos estratificados, determinados pelo nível de qualificação. Assim, a ciência é a forma de conhecimento que se associa aos universos reificados e as representações sociais o que corresponde aos universos consensuais (Moscovici, 1981).

O estudo do corpo a partir da perspectiva das representações sociais torna-se importante uma vez que estas assumem um importante papel na elaboração de formas de ver e viver o corpo, expandindo modelos de pensamento e de comportamento a ele relacionados (Jodelet, 1984). O corpo é associado a padrões estéticos que enfatizam o magro, o jovem e o branco. As representações sociais que contemplam estritamente as questões físicas relativas ao corpo envolvem o embelezamento corporal e facial. Os indicadores da representação social sobre a beleza, por sua vez, estão relacionados à imposição de padrões ou regras socialmente estabelecidas (Camargo, Goetz, Bousfield, \& Justo, 2011; Goetz, Camargo, Bertoldo, \& Justo, 2008).

Todas as interações humanas, tanto as interpessoais como as intergrupais, estão permeadas por representações. A tensão entre 0 conhecido e o não conhecido está presente sempre em nossos universos consensuais, defendendo o que nos é familiar e podendo, assim, originar ideias pré-concebidas e ou preconceituosas:

“No pensamento social, a conclusão tem prioridade sobre a premissa, e nas relações sociais (...) o veredicto tem prioridade sobre o julgamento. Antes de ver e ouvir a pessoa, nós já a julgamos, nós já a classificamos e criamos uma imagem dela" (Moscovici, 2004, p. 58).

Conforme Caetano (2006), formar uma impressão significa organizar a informação disponível acerca de uma pessoa para que seja possível agrupá-la em uma categoria significativa para o indivíduo. Asch (1960) demonstra que para a formação de impressões algumas características são mais centrais e outras mais periféricas, em que cada traço da personalidade do indivíduo proporciona diferentes contribuições para a impressão final. As características centrais têm maior influência do que os traços periféricos porque é a partir dessas características que a impressão se forma.

Tajfel (1982) define os estereótipos como imagens mentais de indivíduos ou fatos que são compartilhados pelas pessoas, podendo ter sua origem na cultura. Elas podem ser amplas ou restritas, possuir uma predisposição favorável ou desfavorável em relação a 
membros de uma determinada categoria, além de estar ou não relacionadas com a cultura e com a experiência comum, passada ou atual. As representações sociais e os estereótipos estão relacionados às imagens construídas pela sociedade de objetos sociais, grupos e pessoas. As representações sociais constituem a forma de explicar e interpretar o mundo em que as pessoas vivem, e a maneira de descrever as pessoas e objetos sociais constituem os estereótipos.

Algumas vezes 0 indivíduo não expressa efetivamente sua representação sobre um objeto, essa representação não verbalizada é denominada de zona muda. É fundamentalmente determinada pela situação na qual a representação é produzida, assim, o fenômeno de desejabilidade social e o contexto grupal podem favorecer a omissão de determinadas representações (Abric, 2005). Conforme Menin (2006) os estereótipos podem estar localizados nas zonas mudas das representações sociais, o indivíduo ou grupo não pretende fazer menção a determinado conteúdo pública ou explicitamente, afim se adequarem às normas sociais vigentes.

Os estereótipos possuem duas funções: sociocognitiva e socioafetiva. A função socioafetiva diz respeito à atribuição de significação afetiva a pessoas ou grupos, podendo ser positiva ou negativa. Já a função sociocognitiva refere-se aos processos mentais que permitem dar um sentido à realidade, simplificando-a, por meio da categorização e generalização de características encontradas nas pessoas ou grupos (Cazals-Ferré \& Rossi, 2007). Categorizar é classificar pessoas ou grupos, geralmente por meio da cultura, das experiências pessoais e crenças transmitidas pela escola, pais, meios de comunicação e demais agentes de socialização (Marques \& Paéz, 2006). A generalização é definida como uma descrição geral, um agrupamento das características individuais dos indivíduos pertencentes à determinada classe (Tajfel, 1982).

Tajfel (1982) afirma que a articulação entre estereótipos sociais favoráveis ou desfavoráveis, positivos ou negativos, resulta na produção de sentimentos de aceitação ou rejeição de grupos. Quando associados a valores e sentimentos negativos esses estereótipos constituem estruturas psicológicas mais complexas chamadas preconceitos sociais. A complexidade deve-se a presença de sentimentos negativos ou positivos em relação a um objeto social ou um grupo (Krüger, 2004). De acordo com Tajfel (1982), quanto maior for o clima de tensão entre os grupos, mais os estereótipos traduzirão hostilidade e negativismo.

As atitudes preconceituosas podem ser formadas por fatores ligados a pertença a um grupo e adoção de seus valores. Assim, o preconceito é uma disposição a uma reação desfavorável frente a um indivíduo ou grupo, baseando-se na sua pertença a uma classe ou categoria, ou seja, um estereótipo (Cazals-Ferré \& Rossi, 2007). Allport (1979) caracteriza o preconceito como uma atitude negativa frente a uma 
pessoa baseada na crença de que essa pessoa possui características negativas atribuídas a um grupo.

O preconceito social compreende motivações e sentimentos negativos, de natureza aversiva e excludente, dirigidos a determinados grupos devido a suas características mais significativas, sem levar em conta a uniformidade e homogeneidade dessas características no grupo (Cazals-Ferré \& Rossi, 2007). O preconceito pode ser manifestado por meio de tratamento hostil, como verbalização negativa das características do grupo, rejeição de contato íntimo, ataque físico e extermínio do grupo nos casos mais graves (Allport, 1979).

O preconceito colocado em ação é caracterizado como discriminação, quando há uma ação, um comportamento. Portanto, a discriminação é um efeito do preconceito, que compreende um tratamento injusto, um relacionamento desigual e avaliação desfavorável orientada ao grupo alvo de preconceito e seus membros (Krüger, 2004). De acordo com Garcia-Marques e Garcia-Marques (2003) a discriminação é um dos processos psicológicos mais básicos relacionados com estereótipos e preconceitos.

A mídia contribui para as discussões acerca da idealização de corpo, principalmente do feminino, ao expandir entre os grupos de mulheres, em especial as jovens, o ideal de magreza, reforçando o estigma de ser "gordinha". De acordo com Moscovici (1981) e Rouquette (1986) a comunicação de massa é uma poderosa e dinâmica maneira de elaborar representações sociais, pois disponibiliza a cada dia muito material e conteúdo no cotidiano dos indivíduos e grupos.

Além disso, a mídia, em especial a internet, constitui-se num espaço privilegiado em que é possível realizar aquilo que não é permitido pela sociedade, em que as normas sociais que a regem podem ser burladas sob a garantia de anonimato, ou com o objetivo de filiação a grupos específicos (Camargo, Alves, Morais, \& Koelzer, 2012). Assim, opiniões e pontos de vistas contranormativos podem ser livremente disseminados, reforçando atitudes de preconceito e justificando a discriminação.

Uma pessoa pode ser vítima de preconceitos em decorrência de diversos fatores, por pertencer a uma determinada categoria sexual ou etnia, por sua idade ou atributos físicos e mentais. O preconceito impõe, por conseguinte, generalizações desfavoráveis a membros de grupos particulares. Em uma sociedade que valoriza o corpo magro, principalmente o feminino, a mulher obesa pode ser alvo de preconceito e comportamentos discriminatórios reforçados pela mídia. Desse modo, este estudo teve como objetivo analisar comentários deixados por internautas com relação à reportagem sobre uma série fotográfica que propunha identificar o preconceito por meio do olhar dos indivíduos fotografados. 


\section{Método}

Trata-se de um estudo documental e exploratório. Envolve documentos que não receberam tratamento analítico: comentários que tiveram como estímulo indutor uma reportagem online envolvendo fotografias. Por meio dessa reportagem na internet foram veiculadas fotos, que segundo a fotógrafa, registram o preconceito no olhar das pessoas. As fotos foram tiradas em Nova York e apresentam uma mulher obesa, loira e branca, realizando diversas atividades comuns no dia-a-dia em lugares públicos, como se alimentar, se localizar geograficamente por meio de um mapa ou tomar banho de mar. As fotos focalizam o olhar das pessoas que observam as ações da mulher obesa, nesses diversos espaços, sendo que nessa reportagem online tais olhares são associados à expressão de preconceito.

Esta reportagem foi divulgada em um site brasileiro, gerando cerca de 172 comentários feitos por internautas, a partir do cadastro em uma rede social. É importante salientar que a divulgação da notícia no site limitou-se a conceder informações de maneira imparcial, trazendo as fotos, mas não apresentando explicitamente juízo de valor, envolvendo dados de domínio público e sem identificação dos participantes.

Neste estudo serão analisados os comentários online postados sobre - conteúdo da reportagem que se propõe a identificar o olhar preconceituoso. Dentre os 172 comentários postados no site $50 \%$ pertenciam a pessoas do sexo masculino. Por meio de um botão localizado abaixo de cada comentário, estes podiam ser classificados por outros internautas como positivos. Os critérios para a avaliação dos comentários cabiam a cada internauta que fazia esta avaliação. Observou-se que $78 \%$ dos comentários postados obteve uma apreensão positiva.

Para a análise dos comentários foi utilizada a técnica de análise lexical de conjuntos de segmentos de texto, na qual os dados foram submetidos a uma Classificação Hierárquica Descendente (CHD), realizada pelo programa informático Iramuteq. Conforme Camargo e Justo (2013), esta análise visa obter classes de Unidades de contexto elementar (UCE) que, ao mesmo tempo, apresentam vocabulário semelhante entre si e vocabulário diferente das UCE das outras classes. As classes geradas a partir da classificação hierárquica descendente representam o contexto de sentido das palavras e podem apontar representações sociais ou elementos de representações sociais sobre o objeto social estudado (Camargo, 2005). A interface do Iramuteq viabiliza a recuperação dos segmentos de texto associados a cada classe no corpus original, 
obtendo-se o contexto das palavras estatisticamente significativas, o que possibilita uma análise mais qualitativa dos dados (Camargo \& Justo, 2013).

Cada comentário online foi considerado uma $\mathrm{UCl}$ (Unidade de contexto inicial). Após Classificação Hierárquica Descendente (CHD) simples foram considerados para inserção em cada classe os elementos cuja frequência foi maior que a média de ocorrências no corpus e que a associação com a classe determinada pelo valor de qui-quadrado fosse igual ou superior a 3,84.

\section{Resultados}

Os dados obtidos por meio dos comentários foram analisados a partir de um corpus de análise. O conteúdo do corpus compreende posicionamentos favoráveis e/ou desfavoráveis à notícia do ensaio fotográfico. O corpus foi composto por 172 textos, as quais continham 1711 palavras analisáveis (indicadoras de sentido) que ocorreram 8145 vezes, sendo a média de ocorrência de 4,76 vezes por palavra. A análise hierárquica descendente reteve $79.07 \%$ dos ST (segmentos de texto) do corpus (136 dos $172 \mathrm{ST}$ ), organizadas em quatro classes, como indica a Figura 1. Ela contém: a) o nome do corpus e a quantidade de ST retidas nele; b) o nome das classes e o número de ST que a compõem; c) a descrição das classes e das palavras que mais se associaram a ela, em função do $x^{2}$ e da frequência média de ocorrência das palavras. 


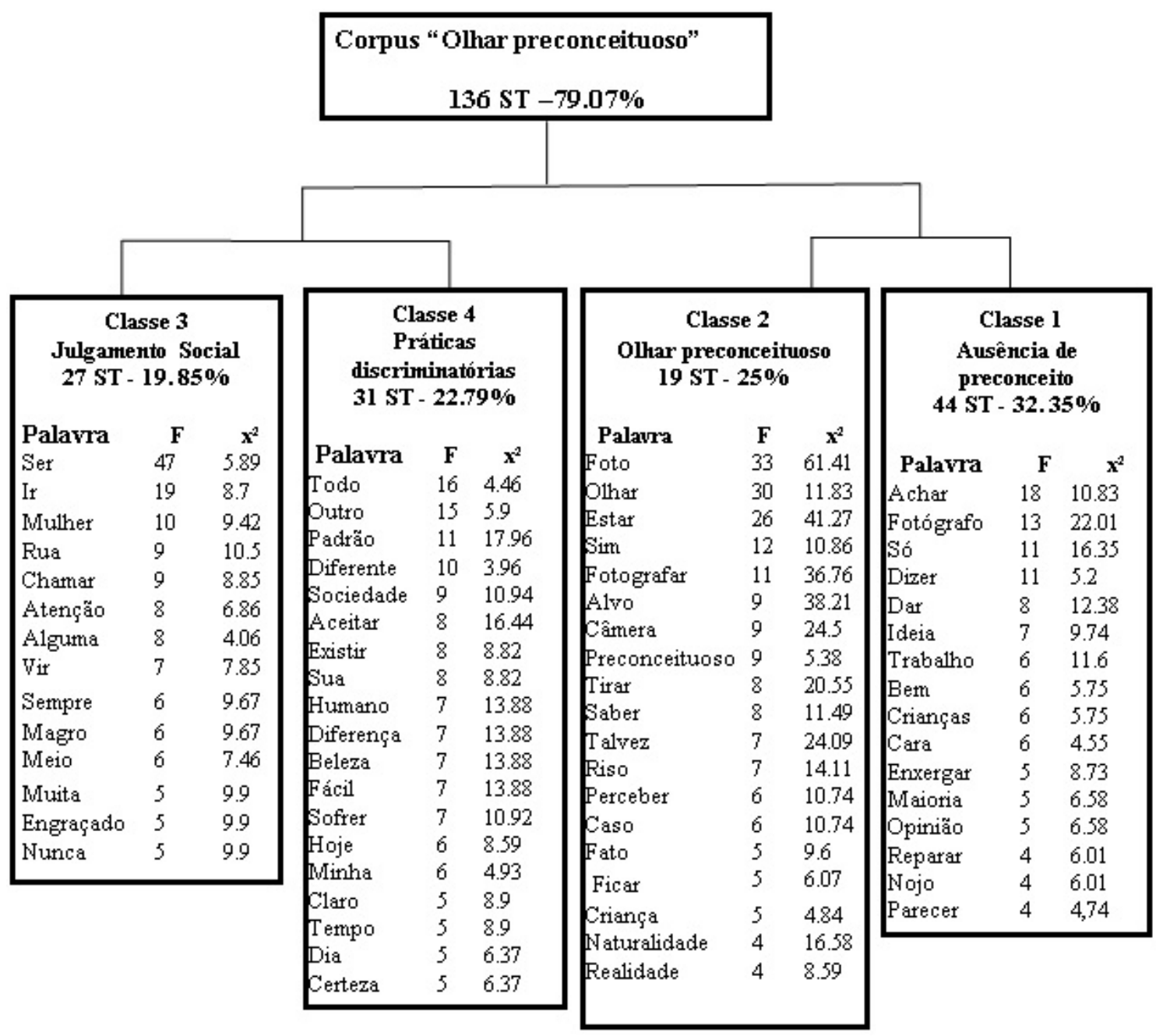

Figura 1- Dendograma de classes sobre o olhar preconceituoso

O corpus sofreu uma primeira partição em dois subcorpus, indicando a classe 1 e 2 em oposição às classes 4 e 3 . A partir disso, houve uma segunda partição, opondo a classe 1 à classe 2 e opondo a classe 4 à 3.

As classes 1 e 2 estão relacionadas principalmente com a fotógrafa e o trabalho realizado por ela. São apresentadas palavras como "fotografar", "tirar", "foto" na classe 2, e "fotógrafo", "trabalho", "opinião" e "maioria" na classe 1. As palavras de ambas as classes remetem a uma opinião acerca da ideia da fotógrafa em realizar esse trabalho e não do conteúdo das fotos em si. A classe 1 recebeu o menor número de apreciações positivas por parte dos leitores da página na internet, demonstrando que possivelmente um menor número de internautas percebia o olhar preconceituoso nas fotos. Nessa classe os comentários representam uma opinião contrária ao ensaio fotográfico, em que se procura demonstrar que a fotógrafa não obteve sucesso no propósito de captar olhares preconceituosos, como no exemplo: 
"A maioria esmagadora das fotos mostra nada mais do que olhares de relance, que acabam não dizendo absolutamente nada sobre as pessoas. Algumas fotos até parecem mostrar algum tipo de preconceito, mas mesmo assim fica muito subjetivo dizer a atitude das pessoas é preconceitusa só olhando as fotos. Por exemplo, a menina de calça colorida, na foto parece, só de relance, estar rindo da mulher, mas se observarmos direito parece mesmo é que ela tá conversando com o rapaz que a acompanha. Como eu disse antes, é muito relativo julgar só pela foto" (homem, ST 21).

A classe 2 , também relacionada ao trabalho da fotógrafa, refere-se às fotos como demonstrações de atitudes preconceituosas. Nessa classe encontram-se os comentários com maior número de apreciações positivas efetivadas pelos leitores da página online, o que parece indicar que a maior parte dos comentários identificam atitudes preconceituosas em relação à mulher obesa nas fotografias. A maioria dos participantes desta classe, representada pelo sexo feminino, identificou "o olhar preconceituoso" por meio das fotos da reportagem, como no exemplo:

"Achei belíssimo esse trabalho, porque a função de quem produz imagens não é só captá-las, mas sim pensar sobre elas. Não vejo uma postura tendenciosa do fotógrafo, ao contrário, são fotos quase que amadoras de tão realistas, e sim a cara das pessoas estão estampadas de ideia, pré-ideia ou preconceito, sejam eles porque a artista é gorda, mulher, branca. Seja qual for a razão há um preconceito na cara de cada um" (mulher, ST 102).

A classe 4 constitui-se como maior classe gerada, sendo representada principalmente pelo sexo masculino. Seus elementos fazem referência ao preconceito enquanto objeto de discussão social, destacando sua presença ou ausência em algumas fotos, como forma de exemplificar algo que faz parte da realidade social. As palavras tais como "padrão", "diferente", "sociedade" e "existir" remetem ao contexto social atual e suas relações com as práticas discriminatórias, conforme o excerto:

“Eu acho que cada foto tem o seu contexto, algumas realmente se encaixam no fato da situação em si ser estranha e a pessoa por não estar entendendo o que está acontecendo, olhar a outra e não seria um preconceito, mas também há outras fotos que se encaixam no que diz respeito a preconceito, diria que as fotos não foram feitas respeitando uma linha de pensamento e padrão de situação, mas há fotos que servem sim para ver o 
preconceito e infelizmente são as que mostram pessoas jovens, o que mostra como uma porcentagem grande dessa juventude de hoje em dia está se comportando" (homem, ST 16).

Já a classe 3 se diferencia por apresentar elementos associados ao julgamento social: "ser", "chamar", "atenção" e "engraçado". Essa classe apresenta o preconceito como um ato de julgamento inerente ao indivíduo e sua situação na sociedade, na condição de proteção diante de situações aversivas ou diferentes, como um mecanismo de adaptação. São apresentadas justificativas biológicas e psicológicas que indicam a atitude de julgar como algo neutro, algo natural, em que não há conotação positiva ou negativa sobre 0 ato preconceituoso, como no excerto:

"Já encheu o saco essa de preconceito, esquecem que uma das características que permitiram a nossa espécie estabelecer-se e continuar sobrevivendo no planeta é justamente o julgar. Para sobrevivermos é fundamental, pra averiguar se algo está adequado para se consumir ou não. Se é algo absolutamente natural, qual é o problema das pessoa olharem e realizarem sua reflexão sobre algo que chama atenção? A gente não faz isso o tempo todo? Duvido que ela não faça também, mas é engraçado que alguns grupos quando se sentem de alguma forma discriminados tratam logo de agir como se fossem absolutamente íntegros e os demais carrascos" (mulher, ST 62).

Portanto, pode-se perceber diferentes enfoques nas classes acima apresentadas. Enquanto algumas focam no trabalho da fotógrafa e tecem comentários a esse respeito, seja em aprovação ou desaprovação, outras classes trazem um enfoque no conteúdo das fotos e no que elas pretendiam captar, o preconceito.

\section{Discussão}

Em geral, os dados analisados refletem pouca autoimplicação dos indivíduos em relação ao preconceito. A força da norma social faz com que as pessoas identifiquem o preconceito nas imagens, mas que evitem assumir atitudes pessoais preconceituosas. Ao remeterem-se ao julgamento ou ao ato preconceituoso os participantes atribuem à ação à sociedade, a outro indivíduo, à modelo ou à fotógrafa, não fazendo referência a si mesmo durante a elaboração dos comentários.

De acordo com a abordagem estrutural há, no núcleo central das representações sociais, elementos ativados e desativados que podem 
ter ativação de acordo com a situação, com o contexto. A zona muda faz parte da consciência dos indivíduos, contudo, ela não é verbalizada porque o indivíduo ou grupo não pretende fazer menção a determinado conteúdo pública ou explicitamente. É fundamentalmente determinada pela situação na qual a representação é produzida, por isso o fenômeno de desejabilidade social e o contexto grupal podem favorecer a omissão de determinadas representações (Abric, 2005).

Portanto, é necessário considerar a internet, e em específico as redes sociais, como campo de exposição no qual o sujeito, por meio de seu perfil online, poderia ser identificado por seus pares. É possível que esse contexto tenha favorecido a ocorrência da zona muda, sendo necessário o desenvolvimento de novas pesquisas que considerem o anonimato ou utilizem de estratégias metodológicas para minimizar os efeitos do fenômeno de desejabilidade social.

Denise J odelet (1989b), em seu estudo sobre a representação social da loucura, percebeu que apesar de evitar menção de atos discriminatórios pessoais, o comportamento e os rituais de uma comunidade revelavam a sustentação de relações desiguais, na qual o doente era evitado, por meio da omissão de sua presença. Nesse sentido, os participantes da presente pesquisa parecem também evitar menção às práticas discriminatórias. No entanto, em seus comentários fazem a separação entre o obeso e a sociedade. Essa relação está presente principalmente nas classes 1 e 2 , nas quais 0 trabalho da fotógrafa é discutido a partir da ausência ou presença do "olhar preconceituoso" nas fotos, sem fazer menção à modelo obesa e sua participação nas fotos.

Na classe 1 predominam elementos relativos às fotos e a ausência do preconceito nos "olhares destacados pela fotógrafa". Contudo, a ausência de menção à modelo obesa e constante referência à fotógrafa enquanto gerador do preconceito nas fotografias reflete um discurso ideológico. Tal discurso inicialmente nega o objeto de preconceito e posteriormente nega o preconceito pessoal, responsabilizando a sociedade pela existência desse preconceito (Camino, Silva, Machado, \& Pereira, 2001).Dados similares foram encontrados por Pereira, Torres e Almeida (2003), que realizaram um estudo do preconceito na perspectiva das Representações Sociais. Para tanto, os autores realizaram análise da influência de um discurso justificador da discriminação no preconceito racial e identificaram como elementos constitutivos do campo representacional a crença na existência de um preconceito generalizado na sociedade brasileira. Assim como os dados dos participantes referentes à classe 1 nesta pesquisa, a pesquisa de Pereira, Torres e Almeida (2003) indica que individualmente as pessoas julgam que não são preconceituosas, mas evitam o contato com o objeto alvo de discriminação. 
$\mathrm{Na}$ classe 3 estão presentes elementos associados ao julgamento social, além de aspectos biológicos e psicológicos utilizados como justificativas para as práticas de julgamento. Os participantes fazem menção ao conceito de inconsciente e trazem aspectos justificadores do preconceito em relação aos indivíduos obesos a partir da genética e das relações sociais. Nessa classe há a ênfase de que a construção de estereótipos é natural e, por consequência, a discriminação em relação à pessoa obesa é considerada como um ato neutro, sem conotação negativa.

Echabe (1997) aponta que na década de 1980, nos estudos predominantes sobre preconceito e racismo, ambos eram considerados uma consequência "normal", "natural" de processos cognitivos humanos. Nos anos 1940, 1950, e nos 1970, o estudo do preconceito é dominado por uma perspectiva individualista. Como resultado, a maioria das intervenções psicossociais é focada em mudar "mentes individuais" (Echabe, 1997).

De acordo com Contarello (2007), na vida cotidiana "os amadores" aparentam ser potencialmente mais motivados na direção do conhecimento especializado. A mídia exerce a função de mediadora entre 0 universo reificado (ciência) e 0 universo consensual possibilitando que as teorias sejam transportadas para o senso comum (Moscovici, 1978).

As explicações biológicas e psicológicas denotam a transformação dessas concepções em saber de senso comum. Nesse contexto, "os processos de exclusão social podem ser sustentados por teorias científicas ou de senso comum adotadas na sociedade" (Lacerda, Pereira, \& Camino, 2002, p.175). Assim, as explicações baseadas em modelos teóricos desenvolvidos no domínio científico, quando transformadas em saber de senso comum, podem contribuir como justificadoras para os atos discriminatórios.

A classe 2 traz a identificação do "olhar preconceituoso" e a relação das fotos com ações discriminatórias. Nessa classe encontram-se majoritariamente mulheres, sendo que os comentários apresentam o maior número de apreciações positivas por parte dos leitores da página online, o que pode representar um maior nível de concordância com as considerações acerca do preconceito presente nas fotografias.

Apesar do reconhecimento do preconceito como um mecanismo social de diferenciação em relação à pessoa obesa, esta classe representa mais um aspecto relativo à zona muda das representações sociais. Ao atribuir o "olhar preconceituoso" às pessoas das fotos e fazer um comparativo com as ações discriminatórias na sociedade, os participantes não se posicionam como pertencentes dessa sociedade, atribuindo a outro as práticas de discriminação. Ao relatar representações "proibidas ao seu grupo" e atribuindo-as a outros, 
reduz-se o nível de implicação pessoal e a pressão normativa, o que viabiliza a expressão de aspectos da zona muda (Menin, 2006).

Sobre a classe 4 é possível verificar referências ao preconceito enquanto realidade social. Os comentários pertencentes a essa classe não fazem referência exclusivamente ao ensaio fotográfico nem à obesidade, mas fazem alusão às práticas discriminatórias e atitudes que denotam preconceito em relação à pessoa obesa em seu contexto social. Do mesmo modo, no estudo de Guimelli e Deschamps (2000) sobre a representação social acerca dos ciganos, foi possível identificar que os termos com conotação mais negativa ou contranormativa em relação ao objeto emergiram com maior frequência quando os sujeitos falavam em nome das "pessoas em geral" e em relação ao "preconceito em geral".

Nesse sentido, de forma equivalente, a obesidade parece ocupar espaço na zona muda nas representações sobre o "olhar preconceituoso". Isso porque há uma ambivalência normativa que sustenta a valorização do corpo magro, mas que concomitantemente repudia formas explícitas de preconceito, o que faz com que 0 indivíduo queira se filiar ao grupo socialmente aceito (magros), mas não possa demonstrar explicitamente sua diferenciação ao exogrupo (obesos).

Em todas as classes destacadas a presença das normas sociais é atuante. Seja por meio da atribuição de uma representação a outro, o que caracteriza a zona muda, por adequação à norma antidiscriminatória ou atribuição do preconceito justificado na ação do indivíduo alvo de discriminação.

\section{Considerações finais}

Com a supervalorização da juventude como um bem em si mesmo surge o ideal de um corpo portador de medidas específicas, voltadas ao corpo magro e com curvas, enquanto o gordo, sendo indesejado, é isolado pela sociedade e associado ao descuido e ao relaxamento (Veiga, 2012). Essa é uma questão social, além de política e econômica, pois diz respeito à relação entre os indivíduos, envolve estigmas, discriminação e preconceito.

As representações sociais compõem um saber prático acerca de problemáticas interpessoais e auxiliam na elaboração coletiva, a qual depende da sociedade, de sistemas de poder e de ideologia, e não do fenômeno individualizado. Assim, a questão torna-se social e não individual. Segundo Rouquette (1996), os padrões rigorosos de beleza e o compartilhamento de representações sociais do corpo têm impacto na insatisfação corporal feminina e devem ser compreendidos dentro de uma arquitetura de pensamento social. 
Os participantes parecem evitar menção às práticas discriminatórias, porém referem-se ao obeso separando-o da sociedade. Parece haver pouca autoimplicação dos indivíduos em relação ao preconceito. Entretanto, as pessoas identificam o preconceito nas fotografias, atribuindo o olhar preconceituoso à sociedade, a outro indivíduo, à modelo ou à fotógrafa.

A ausência do aparecimento de um discurso individual com estereótipos negativos não implica necessariamente no desenvolvimento de uma sociedade mais tolerante. Os participantes deste estudo não se posicionam de forma discriminatória em relação ao obeso, mas ao mesmo tempo desejam se diferenciar desse grupo cuja imagem não é socialmente desejável, sendo possível que práticas discriminatórias em relação ao obeso ainda sejam adotadas. Assim, a obesidade como algo indesejável parece ocupar espaço na zona muda nas representações sobre o "olhar preconceituoso".

A variável "sexo" parece não influenciar de modo significativo nos elementos representacionais analisados por meio dos comentários online. Novos estudos devem ser incentivados na intenção de apresentar dados comparativos de forma quantitativa, considerando a possível influência da variável sexo. Do mesmo modo, parece relevante analisar em novas pesquisas a relação de contexto referente às representações sociais, bem como realizar um estudo comparativo por meio da realização de grupos focais que possam igualmente discutir a temática por meio da apresentação de imagens, em diferentes contextos, controlando variáveis, o que não foi possível identificar na amostra utilizada.

Por fim, é importante ressaltar que os resultados apresentados dizem respeito a um grupo específico de pessoas que expressaram sua reação frente à notícia do ensaio fotográfico em questão, portanto não podem ser generalizados. Tratando-se de uma aproximação do fenômeno estudado, compreende-se que é impossível uma completa apreensão dele e que outros estudos são necessários para melhor explorar os elementos representacionais relativos ao preconceito e à obesidade.

\section{Referências}

Abric, J. C. (2005). A zona muda das representações sociais. In: D. C. Oliveira, \& P. H. F. Campos (Orgs), Representações Sociais Uma teoria sem fronteiras (pp. 23-34). Rio de Janeiro: Museu da República.

Allport, G.W. (1979). The nature of prejudice. New York: Basic Books. Asch, S. E. (1960). Psicologia social. São Paulo, Companhia Editora Nacional (volume 2). 
Caetano, A. (2006). Formação de impressões. In J. Vala, \& M. B. Monteiro (Eds.), Psicologia Social (pp. 89-123). Lisboa, Portugal: Fundação Calouste Gulbenkian.

Camargo, B. V. (2005). ALCESTE: um programa informático de análise quantitativa de dados textuais. Perspectivas teóricometodológicas em representações sociais, 1, 511-539.

Camargo, B. V., Goetz, E. R., Bousfield, A. B., \& Justo, A. M. (2011). Representações sociais do corpo: estética e saúde. Temas em Psicologia 19(1), 257-268. Recuperado em 06 de junho de 2014, de http://pepsic. bvsalud.org/scielo. php? pid=S1413389X2011000100021\&script=sci_arttext

Camargo, B. V., Alves, C. D. B., Morais, D. X., \& Koelzer, L. P. (2012). Normas Sociais Relacionadas à Infidelidade no Espaço Virtual. Brazilian Cultural Studies, 1(3), p. 289-304.

Camargo, B. V., \& Justo, A. M. (2013). IRAMUTEQ: um software gratuito para análisede dados textuais. Temas em Psicologia, 21(2), 513-518. Recuperado em 06 de junho de 2014, de http://pepsic. bvsalud.org/scielo. php?script=sci_arttext\&pid=S1 413-389X2013000200016

Camino, L., Silva, P. D., Machado, A., \& Pereira, C. (2001). A face oculta do racismo no Brasil: uma análise psicossociológica. Revista de psicologia política, 1(1), 13-36.

Cazals-Ferré, M. P., Rossi, P. (2007). Psicologia: elementos de psicologia social. Portugal: Porto Editora.

Contarello, A. (2007). Representações Sociais e o Mundo da Ciência: gênero, número e caso em ciência, tecnologia e vida cotidiana. In A. S. P. Moreira, \& B. V. Camargo (Orgs), Contribuições para a Teoria e o Método de Estudo das Representações Sociais (pp.203-222). J oão Pessoa: Editora Universitária da UFPB.

Dantas, E. H. (1994). Pensando o corpo e o movimento. Rio de janeiro: Shape.

Echabe, A.E. (1997). Socio-psychological approaches to racism: a critical review. Paperson social representations, 6(1), 1-11.

Fischler, C. (1995). Obeso benigno/obeso maligno. In: D. B. Sant'anna (Org). Políticas do corpo (pp. 121-139). São Paulo: Estação Liberdade, 1995.

Garcia-Marques, T., \& Garcia-Marques, L. (2003). Os estereótipos e sua influência no processamento de informação. Lisboa: ISPA.

Goetz, E.R., Camargo, B.V., Bertoldo, R.B., \& Justo, A. M. (2008). Representação social do corpo na mídia impressa. Psicologia e Sociedade, 20(2), 226-236. Recuperado em 06 de junho de 2014, http://www.scielo.br/scielo.php?script=sci_arttext\&pid=S0102$71822008000200010 \&$ Ing =en\&tlng=pt. _ 10.1590/S010271822008000200010

Goetz, E. R. (2013). Beleza e plasticomania. Curitiba: Juruá. 
Guimelli, C., \& Deschamps, J. C. (2000). Effets de contexte sur la production d'associations verbales. Le cas des représentations sociales des Gitans. Cahiers internationaux de psychologie sociale. Recuperado em 06 de junho de 2014, de http://psycnet. apa.org/psycinfo/2000-12644-003

Haboush, A., Warren, C. S., \& Benuto, L. (2011). Beauty, Ethnicity, and Age: Does Internalization of Mainstream Media Ideals Influence Attitudes Towards Older Adults? Sex roles, 66(9-10), 668-676. Recuperado em 06 de junho de 2014, de http://link.springer.com/article/10.1007/s11199-011-0102-

6\#page- 1

Herscovici, C.R. (1997). A escravidão das dietas: um guia para reconhecer e enfrentar os transtornos alimentares ( $F$. S. Francisco, Trad.). Porto Alegre: Artes Médicas, (Obra original publicada em 1996).

Krüger, H. (2004). Cognição, estereótipos e preconceitos sociais. In M. E. O. Lima \& M. E. Pereira (Orgs.), Estereótipos, preconceitos e discriminação: perspectivas teóricas e metodológicas. (pp. 23-40). Salvador: EDUFBA.

Jodelet, D. (1984). The representation of the body and its transformations. In R. Farr \& S. Moscovici (Eds.), Social representations (pp. 211-238). Cambridge, UK: Cambridge University Press.

Jodelet, D. (1989a). Les representations sociales. Paris, PUF.

Jodelet, D. (1989b). Folie et representations sociales. Paris: PUF.

Jodelet, D. (2001). Representações sociais: um domínio em expansão. In: Jodelet, D. (Org.). As representações sociais. (pp. 187-203). RJ: Eduerj. Recuperado em 06 de junho de 2014, de http://spw.estacio.br/media/3432753/jodelet-drs-umdominio-em-expansao.pdf

Lacerda, M., Pereira, C., \& Camino, L. (2002). Um estudo sobre as formas de preconceito contra homossexuais na perspectiva das representações sociais. Psicologia: Reflexão e Crítica, 15(1), 165-178. Recuperado em 06 de junho de 2014, de http://www.scielo.br/scielo. php?script=sci_arttext\&pid=S010279722002000100018

Marques, J., \& Paéz, D. (2006). Processos cognitivos e estereótipos sociais. In: J. Vala, \& M.B. Monteiro (Coord). Psicologia Social. 7a Ed. (pp. 333-386). Lisboa: Calouste Gulbenkian.

Menin, M. S. D. S. (2006). Representação social e estereótipo: a zona muda das representações sociais. Psicologia, Teoria e Pesquisa, 22(1), 43-51. Recuperado em 06 de junho de 2014, de http://www.scielo.br/scielo. php?script=sci_arttext\&pid=S0102$37722006000100006 \&$ Ing $=$ en\&tIng $=$ pt.

$10.1590 /$ S010237722006000100006 
Moscovici, S. (1978). A representação social da psicanálise. Rio de Janeiro: Zahar, 1978.

Moscovici, S. (1981). On social representations. In: J. P., Forgas. Social Cognition. London: Academic press.

Moscovici, S. (2000). The phenomenon of social representations. In S. Moscovici \& G. Duveen (Orgs.), Social representations: Explorations in social psychology (pp.18-77). Cambridge: Polity.

Moscovici, S. (2004). Representações Sociais: Investigações em psicologia social. 2 ed. Rio de Janeiro: Vozes.

Novaes, J. V., \& Vilhena, J. (2003). De cinderela à moura torta: sobre a relação mulher, beleza e feiúra. Revista Interações, VIII(15), 9-36. Recuperado em 06 de junho de 2014, de http: // pepsic. bvsalud.org/scielo.php?script=sci_arttext\&pid=S1 413-29072003000100002\&lng=pt\&tIng=es

Palmonari, A., \& Cerrato, J. (2011). Representações sociais e psicologia social. In: A. M. O. Almeida, M. F. S. Santos, \& Z. A. Trindade (Orgs.). Teoria das Representações Sociais: 50 anos (pp. 305-334). Brasília: Technopolitik.

Pereira, C., Torres, A. R. R., \& Almeida, S. T. (2003). Um estudo do preconceito na perspectiva das representações sociais: análise da influência de um discurso justificador da discriminação no preconceito racial. Psicologia: Reflexão e Crítica, 16(1), 95-107. Recuperado em 06 de junho de 2014, de http: //www.scielo.br/scielo.php?script=sci_arttext\&pid=S0102$79722003000100010 \&$ Ing =en\&tlng=pt. $\quad$ 10.1590/S010279722003000100010

Rouquette, M.L. (1986). La comunicación de massas. In: Moscovici, S(Ed.). Psicologia Social: Pensamiento y vida social, (pp. 641647). Buenos Aires: Paidós.

Rouquette, M. L. (1996). Représentations et idéologie. In J. C. Deschamps \& J. L. Beauvois (Eds.), Des attitudes aux attributions (pp. 163-173). Grenoble: Presses Universitaires de Grenoble.

Stearns, P.N. (1997). Fat history: bodies and beauty in the modern west. New York and London: New York University Press.

Tajfel, H. (1982). Grupos humanos e categorias sociais. Vol. 1. Lisboa: Horizonte.

Tolman, D.L. \& Debold, E. (1994). Conflicts of body and image: female adolescents, desire, ash the no-body body. In P. Fallon, M. A. Katzman, \& S. C. Wooley. Feminist Perspective Oneating Disorders. New York: The Guilford Press.

Vasconcelos, N. A. D., Sudo, I., \& Sudo, N. (2004). Um peso na alma: O corpo gordo e a mídia. Revista Mal Estar e Subjetividade, 4(1), 65-93. Recuperado em 06 de junho de 2014, de 
http://pepsic. bvsalud.org/scielo.php?script=sci_arttext\&pid=S1 518-61482004000100004\&lng=pt\&tIng=pt

Veiga, M. R. M. (2012). Mulheres na meia-idade: corpos, envelhecimentos e feminilidades. (Dissertação de Mestrado). Universidade Federal de Santa Maria, Santa Maria, RS.

Wolf, N. (1992). O mito da beleza: como as imagens da beleza são usadas contra as mulheres (W. Barcellos, Trad.). Rio de Janeiro: Rocco (Obra original publicada em 1991).

\section{Endereço para correspondência \\ Larissa Papaleo Koelzer}

Universidade Federal de Santa Catarina - UFSC

Laboratório de Psicologia Social da Comunicação e Cognição - LACCOS

Rua Alba Dias Cunha, 147 apto 606 bloco 1, Trindade, CEP 88036-020, Florianópolis - SC, Brasil

Endereço eletrônico: larissapk@hotmail.com

\section{Amanda Castro}

Universidade Federal de Santa Catarina - UFSC

Laboratório de Psicologia Social da Comunicação e Cognição - LACCOS

Servidão Pedro Manoel da Silveira, 280B, Tapera, CEP 88948-520, Florianópolis SC, Brasil

Endereço eletrônico: amandacastrops@gmail.com

\section{Andréa Barbará S. Bousfield}

Universidade Federal de Santa Catarina - UFSC

Centro de Filosofia e Ciências Humanas, Departamento de Psicologia

Campus Universitário, Trindade, CEP 88040-900, Florianópolis - SC, Brasil

Endereço eletrônico: andreabs@gmail.com

\section{Brigido Vizeu Camargo}

Universidade Federal de Santa Catarina - UFSC

Centro de Filosofia e Ciências Humanas, Departamento de Psicologia

Campus Universitário, Trindade, CEP 88040-900, Florianópolis - SC, Brasil

Endereço eletrônico: brigido.camargo@yahoo.com.br

Recebido em: 06/06/2014

Reformulado em: 09/09/2015

Aceito para publicação em: 24/03/2016

\section{Notas}

* Mestre em Psicologia.

** Mestre em Psicologia

*** Doutora em Psicologia

$* * * *$ Doutor em Psicologia 